\title{
Short communication: Breed differences affecting dairy cattle welfare in traditional alpine tie-stall husbandry systems
}

\author{
S. Mattiello, ${ }^{1}$ M. Battini, E. Andreoli, and S. Barbieri \\ Università degli Studi di Milano, Dipartimento di Scienze Animali, Via Celoria 10, 20133 Milan, Italy
}

\begin{abstract}
The aim of this investigation was to compare the prevalence of indicators of poor welfare among 5 Italian cattle breeds (Italian Holstein-Friesian, Italian Bruna, Pezzata Rossa Italiana, Grigia Alpina, and Pezzata Rossa d'Oropa) kept in tie-stalls in the Italian Alps under similar housing and management conditions. We recorded the presence of integument alterations (hairless patch areas, lesion/swollen areas, or overgrown claws) and lameness in 612 cows. Additionally, we checked 834 cows for the presence of physical malformations ("open" shoulders). In general, the prevalence of welfare problems showed a decreasing trend from the more productive to the less productive breeds. Local breeds (Grigia Alpina and Pezzata Rossa d'Oropa) showed a significantly lower prevalence of welfare problems compared with the other 3 breeds, whereas Italian Holstein-Friesian usually had the highest percentage of individuals with problems. No differences were found between Pezzata Rossa Italiana and Italian Bruna, both of which showed fewer problems than Italian HolsteinFriesian. The effect of the breed significantly affected the welfare of dairy cows in tie-stalls in alpine traditional husbandry systems. The prevalence of the negative welfare indicators studied was lower in local breeds, which are better adapted to local breeding conditions. Our results indicate an urgent need to promote changes in the criteria used for genetic selection in the dairy industry and underline the importance of maintaining the diversity of local breeds, which should be carefully chosen for each specific environmental condition.
\end{abstract}

Key words: dairy cattle breed, tie-stall, alpine husbandry system, animal welfare

\section{Short Communication}

In the Italian Alps, dairy cattle are usually housed in tie-stalls during the cold season (Bovolenta et al., 2008). It has been recognized by many researchers (e.g.,

Received July 8, 2010.

Accepted January 14, 2011.

${ }^{1}$ Corresponding author: Silvana.Mattiello@unimi.it
Bloom, 1983; Valde et al., 1997; Mattiello et al., 2005) that the housing of cattle in tie-stalls may result in several problems in terms of welfare. Among them, we can find an increased risk of lameness, of podal and body lesions (Bloom, 1983; Bielfeldt et al., 2005), and of physical malformations (e.g., "open" shoulders; Mattiello et al., 2009). These considerations are clearly expressed in the European Food Safety Authority (EFSA) Scientific Opinion on the overall effects of farming systems on dairy cow welfare and disease (EFSA, 2009a), which negatively rates the effects of housing in tie-stalls and even includes a minority opinion stating that "there is sufficient evidence for poor welfare in dairy cattle held in tie-stalls. It is recommended that dairy cattle should not be routinely kept in tie-stalls as a housing system." However, tie-stalls are traditional husbandry systems in the Italian Alps and some local breeds have been bred under these conditions for a long time; therefore, we hypothesize that different cattle breeds can show different levels of adaptation to this housing system. The aim of this investigation was to compare the presence of some indicators of welfare (such as injuries or physical malformations) in 5 Italian cattle breeds housed in tiestalls in the Italian Alps.

We visited 44 farms located throughout the Italian Alps: 18 farms in Piedmont (Western Alps), 14 farms in Lombardy (Central Alps), and 12 farms in Alto Adige (Eastern Alps) and collected individual data on 612 cows of different breeds: 94 Italian Holstein-Friesian (F), 125 Italian Bruna (B), 79 Pezzata Rossa Italiana (PRI), 44 Grigia Alpina (GA), and 270 Pezzata Rossa d'Oropa (PRO). All animals were housed in tie-stalls and more than one breed was present at the same time on most of the farms, except on Piedmont farms, where the only breed was PRO.

Very few specific differences in housing or management were associated with different breeds. The farms studied presented many common housing and management traits, such as small herd size $(32 \pm 25$ lactating cows/farm), mechanic manure removal (twice/day), the presence of hard flooring materials (concrete or stone), with straw bedding in most cases (except for a few cases with other natural materials, e.g., sawdust or dry fallen leaves), and an average stall length of $175 \pm$ 
Table 1. Average lactation yield per cow by breed deriving from National Breeder Association statistics recorded in 2009 (AIA, 2010)

\begin{tabular}{lcccc}
\hline Breed $^{1}$ & $\begin{array}{c}\text { Controlled } \\
\text { cows }^{2}(\mathrm{n})\end{array}$ & $\begin{array}{c}\text { Milk production } \\
(\mathrm{kg})\end{array}$ & $\begin{array}{c}\text { Fat } \\
(\%)\end{array}$ & $\begin{array}{c}\text { Protein } \\
(\%)\end{array}$ \\
\hline $\mathrm{F}$ & 587,100 & 8,869 & 3.68 & 3.38 \\
$\mathrm{~B}$ & 59,769 & 6,606 & 3.98 & 3.59 \\
$\mathrm{PRI}$ & 30,811 & 6,351 & 3.87 & 3.46 \\
$\mathrm{GA}$ & 5,428 & 4,745 & 3.69 & 3.37 \\
PRO & 1,798 & 1,825 & 3.58 & 3.44 \\
\hline
\end{tabular}

${ }^{1} \mathrm{~F}=$ Italian Holstein-Friesian; $\mathrm{B}=$ Italian Bruna; PRI = Pezzata Rossa Italiana; GA = Grigia Alpina; PRO = Pezzata Rossa d'Oropa. ${ }^{2}$ Registered cows belonging to all Italian farms joining the AIA.

$13 \mathrm{~cm}$. Some differences among breeds existed, such as stall width: $\mathrm{F}=108 \pm 13 \mathrm{~cm} ; \mathrm{B}=113 \pm 12 \mathrm{~cm}$; PRI $=106 \pm 14 \mathrm{~cm} ; \mathrm{GA}=121 \pm 3 \mathrm{~cm} ; \mathrm{PRO}=107 \pm 8$ $\mathrm{cm}$. About half of the animals (independently of breed) were housed in stalls with presence of partitions and of mats in the lying down area. The only exceptions were PRO farms, where $94 \%$ of animals were housed without partitions and without mats. The only remarkable management difference was the possibility of access to pasture, that was given to $31 \%$ of $\mathrm{F}, 82 \%$ of $\mathrm{B}, 49 \%$ of PRI, $0 \%$ of GA and $100 \%$ of PRO.

Although $\mathrm{F}$ and, to a lesser extent, B are widespread breeds specifically selected for milk production, the other breeds are officially regarded as dual-purpose breeds. However, during the last decades, PRI underwent a strong selective pressure, leading to a current milk yield similar to that of $\mathrm{B}$, whereas GA and PRO exhibit low levels of milk production and are considered rustic breeds, well adapted to local conditions, mainly Bolzano and Trento provinces (Eastern Alps) for GA, and Biella and Vercelli provinces (Western Alps) for PRO. The PRO breed has a particularly limited spread and numerical consistency (7,800 heads in 450 farms; Lucchesi and Mattiello, 2008), yet it has a local importance for the production of typical cheese (Battaglini et al., 2000). Table 1 summarizes milk production traits deriving from national statistics (AIA, 2010), which reflect the genetic improvement for increased productivity of each considered breed.

Animal-based indicators were used to evaluate the welfare state of individual cows. Most of the variables recorded derived from the protocol set up in the EU Welfare Quality ${ }^{\circledR}$ project (Welfare Quality ${ }^{\circledR}, 2009$ ) and they included the presence of integument alterations (hairless patch areas, lesion/swollen areas, or overgrown claws) and lameness. Additionally, we observed shoulder conformation to detect the presence of a physical malformation defined as "open" shoulders (Mattiello, 2008). For this last variable, in the data set we included data collected in a previous survey carried out on 222 cows in 18 farms in Lombardy; therefore, the total sample size for this variable was $834(63 \mathrm{~F}, 225 \mathrm{~B}, 64$ PRI, $39 \mathrm{GA}$, and $270 \mathrm{PRO}$ ). Data were recorded at the end of the indoor period (winter) to minimize the effect of the use of pasture on the considered variables.

For integument alterations, one random side of the cow was scanned from the rear to the front, from a distance not exceeding $2 \mathrm{~m}$. The following alterations (with a diameter $>5 \mathrm{~cm}$ ) were recorded: hairless patch areas (areas with hair loss or extensively thinned hair, skin not damaged, including hyperkeratosis); skin lesions (areas with damaged skin either in form of a scab or a wound) or swollen areas; overgrown claws. Claws were considered normal if they had a plain supporting surface area, if they were not bent, if 2 claws of one leg had the same length, if interdigital space was scarce or apparently null (not visible), and if the angle with the ground was between $45^{\circ}$ and $50^{\circ}$. When 2 or more of these criteria were not respected, the claw was classified as overgrown.

Reliability of integument alteration indicators (hairless patch areas, skin lesions/swollen areas, and overgrown claws) had been checked previously by Danuser and Regula (2001) and Zurbrigg et al. (2005), who reported an agreement from 75 to $80 \%$.

As releasing cows individually from stalls to assess locomotion is not feasible because of time constraints, staff availability, building design, and cows not accustomed to freedom, a validated stall lameness score was adopted for lameness evaluation (Leach et al., 2009a). This "standing scoring" system gives acceptable repeatability ( $70 \%$ agreement within and $89 \%$ between observers; Leach et al., 2009b). In this test, the cow's legs were observed while the cow was standing in her stall: the observer stood behind the animal and encouraged her to move from side to side, applying hand pressure to the hind quarters if necessary. The following indicators were recorded: the feet were rotated outwards or inwards, the cow was resting on one foot more than on the others, the cow was standing avoiding to bear weight on one foot or on part of one foot, the cow was stepping (continuously shifting weight from one foot to another), or the cow was reluctant to bear weight on one foot. When the cow was reluctant to bear weight on 1 foot, or when at least 2 of the other indicators were present, she was considered lame.

In regards to shoulder conformation, special attention was paid to the presence of cows with open shoulders, which can be defined as a particular conformation where the point of the shoulder is oriented outward (not in line with the fore leg) and is accompanied by a closing elbow; this phenomenon seems to be due to a relaxation of the overscapular muscle and to reduced tonicity of the muscles of the scapular region (Mattiello, 2008). Although no scientific evidence of pain 
Table 2. Prevalence of welfare problems in 5 dairy cattle breeds housed in tie-stalls in traditional alpine husbandry systems

\begin{tabular}{lccccc}
\hline & \multicolumn{5}{c}{ Breed $^{1}$} \\
\cline { 2 - 6 } $\begin{array}{l}\text { Indicator } \\
\text { (\% of animals) }\end{array}$ & $\mathrm{F}$ & $\mathrm{B}$ & $\mathrm{PRI}$ & $\mathrm{GA}$ & PRO \\
\hline Hairless patch areas & $40.4^{\mathrm{a}}$ & $20.8^{\mathrm{b}}$ & $21.5^{\mathrm{b}}$ & $2.3^{\mathrm{c}}$ & $3.3^{\mathrm{c}}$ \\
Lesion/swelling areas & $34.0^{\mathrm{a}}$ & $30.4^{\mathrm{a}}$ & $22.8^{\mathrm{a}}$ & $6.8^{\mathrm{b}}$ & $1.5^{\mathrm{c}}$ \\
Overgrown claws & $42.6^{\mathrm{a}}$ & $42.7^{\mathrm{a}}$ & $31.6^{\mathrm{ab}}$ & $20.5^{\mathrm{b}}$ & $8^{\mathrm{c}}$ \\
Lameness & $39.4^{\mathrm{a}}$ & $53.2^{\mathrm{b}}$ & $40.5^{\mathrm{ab}}$ & $2.3^{\mathrm{c}}$ & $1.5^{\mathrm{d}}$ \\
"Open" shoulders & $40.6^{\mathrm{a}}$ & $29.2^{\mathrm{b}}$ & $33.3^{\mathrm{ab}}$ & $11.4^{\mathrm{c}}$ & $0.4^{\mathrm{d}}$ \\
\hline
\end{tabular}

${ }^{\mathrm{a}-\mathrm{d}}$ Values within a row with different superscript are significantly different $(P \leq 0.05)$.

${ }^{1} \mathrm{~F}=$ Italian Holstein-Friesian; $\mathrm{B}=$ Italian Bruna; PRI = Pezzata Rossa Italiana; GA = Grigia Alpina; PRO

$=$ Pezzata Rossa d'Oropa.

or distress in animals with open shoulders is available to date, it represents an evident physical malformation that occurs almost exclusively in tethered cows (Mattiello et al., 2009; Battini et al., 2010).

All data were collected by technicians who previously received the same training. The frequency of animals with presence of hairless patch areas, lesion/swollen areas, overgrown claws, lameness, and open shoulders between each pair of breeds was compared by chi-squared test. For F, B, and PRI, within-breed comparisons were performed by chi-squared test, depending on the possibility of use of pasture.

In general, the prevalence of these welfare indicators showed a decreasing trend from the more productive to the less productive breeds (Table 2). The local breeds (GA and PRO) presented a significantly lower prevalence of all the considered variables compared with the other more productive and selected breeds $(P<$ 0.001 in all comparisons, except for overgrown claws, which did not differ between PRI and GA). In F, the frequency of open shoulders, hairless patch areas, and lesions/swellings was higher than in the other breeds, but these values significantly differed from those of $\mathrm{B}$ and PRI only for hairless patch areas $(P<0.01$ in both cases) and from B only for open shoulders $(P<0.05)$. No differences were found for any of the considered variables between PRI and B, in agreement with previous findings by Corazzin et al. (2009). In regards to this, it should be noted that the milk production level of these 2 breeds is similar (Table 1): lower than F, but dramatically higher than GA and PRO. It is also worth noting that the prevalence of lameness is below the suggested threshold (10\%; EFSA, 2009b) only for GA and PRO, whereas it is much higher in all the other breeds (Table 2). It is acknowledged that lameness and claw health may vary in response to different housing and management conditions, and especially depending on access to pasture (Loberg et al., 2004; Bielfeldt et al., 2005; Corazzin et al., 2010). Within each of the considered breeds, the use of pasture had only a limited (and sometimes contradictory) effect on the prevalence of lameness (Table 3). In fact, although an expected positive effect of pasture on lameness and claw health was recorded in $\mathrm{F}$, this effect was not significant in B and an opposite effect was found on claw health in PRI. These limited differences are possibly due to the fact that data were collected at the end of the winter and therefore the effect of summer grazing was no longer apparent, as demonstrated by Corazzin et al. (2010) and Battini et al. (2010). Both GA and PRO had a lower prevalence of lameness and overgrown claws, in spite of the fact that GA never made use of pasture, whereas PRO always did. These considerations, together with the common housing and management conditions on all the considered farms, suggest that the different prevalence of these problems may be related to a breed effect.

For open shoulders, the much lower value recorded in PRO compared with all other breeds $(P<0.001$ in all comparisons) was due to the presence of only one animal showing this characteristic, and it is interesting to note that this animal was 19 yr old (an age almost impossible to find among Holstein cows).

Table 3. Prevalence of lameness and overgrown claws depending on access to pasture for Italian Holstein-Friesian, Italian Bruna, and Pezzata Rossa Italiana

\begin{tabular}{|c|c|c|c|c|}
\hline \multirow{2}{*}{$\begin{array}{l}\text { Indicator } \\
\text { ( } \% \text { of animals) }\end{array}$} & \multirow{2}{*}{$\begin{array}{l}\text { Use of } \\
\text { pasture }\end{array}$} & \multicolumn{3}{|c|}{ Breed $^{1}$} \\
\hline & & $\mathrm{F}$ & B & PRI \\
\hline \multirow[t]{2}{*}{ Lameness } & Yes & $18.2^{\mathrm{a}}$ & 57.6 & 56.0 \\
\hline & No & $47.8^{\mathrm{b}}$ & 51.7 & 36.6 \\
\hline \multirow[t]{2}{*}{ Overgrown claws } & Yes & $18.2^{\mathrm{a}}$ & 38.5 & $52.0^{\mathrm{a}}$ \\
\hline & No & $52.2^{\mathrm{b}}$ & 55.2 & $26.8^{\mathrm{b}}$ \\
\hline
\end{tabular}

${ }^{\mathrm{a}, \mathrm{b}}$ For each indicator, values within a column with different superscripts are significantly different $(P \leq 0.05)$.

${ }^{1} \mathrm{~F}=$ Italian Holstein-Friesian; $\mathrm{B}=$ Italian Bruna; PRI = Pezzata Rossa Italiana. As Grigia Alpina never had access to pasture and Pezzata Rossa d'Oropa always had access to pasture, these breeds were not included in the analysis. 
Dairy cows have long been selected for increased productivity, which may alter animal fitness causing problems such as increased lameness, skin vulnerability, mastitis, and infertility in high-producing dairy cows (Rauw et al., 1998; Fisher and Webster, 2009). Traits other than milk yield have also been included in selection goals. Body size, together with other type traits, has played a role in altering the appearance of highproducing cows (Hansen, 2000), leading selected breeds to higher space requirements. This might be one of the reasons why $\mathrm{F}, \mathrm{B}$, and PRI housed on mountain farms (which are often old and designed for smaller animals; Mattiello et al., 2005) present a higher frequency of hairless patch areas and of swellings and skin lesions compared with less selected breeds, possibly in response to an increased frequency of collisions with the housing structures. Furthermore, Shanks et al. (1978) reported more cases of skin or skeletal disorders in cows with high genetic potential for milk production, and this might also be related to the higher prevalence of lesions in the more productive breeds.

No difference within breed was found for hairless patch areas, lesion/swollen areas, or open shoulders in response to the possibility of access to pasture. Given that most of the housing and management characteristics of the 5 breeds were similar, and that access to pasture had only limited and sometimes contradictory effects on the considered welfare indicators, our results suggest that the effect of the breed significantly affected the presence of health problems and physical malformations in dairy cows housed in tie-stalls in alpine traditional husbandry systems.

To improve welfare levels of dairy cattle, an urgent need exists to include traits ensuring or enhancing animal welfare in breeding programs (EFSA, 2009a,b; Fisher and Webster, 2009) and to prevent the loss of biological and genetic diversity of local breeds, which have the capacity to adapt to specific environmental conditions (Sandøe et al., 1999).

According to our results, the effect of cattle breed (highly selected vs. local breeds) should be taken into account when risk assessment for dairy cattle welfare is carried out (Mueller-Graf et al., 2008), as identifying the target populations might be a critical point in traditional alpine husbandry systems.

\section{ACKNOWLEDGMENTS}

The authors thank all the people who were involved in the collection of field data [Alessandro Bettini (Sondrio, Italy), Christine Klotz (Versuchzentrum Laimburg, Bozen, Italy), and Vittorio Lucchesi (A.S.L. BI, Biella, Italy] and all the farmers who collaborated with this survey, devoting some of their precious time to the development of the research in order to improve animal welfare. Special thanks also to Elisabetta Canali, Michela Minero, Valentina Ferrante, and Daniela Baroli (all from Università degli Studi di Milano, Dipartimento di Scienze Animali) for sharing their knowledge acquired in the Welfare Quality project that made possible the training of the observers. Finally, we acknowledge the two anonymous reviewers for their precious comments that stimulated us to perform further analysis, helping to strengthen our conclusions. Preliminary results of this research were presented at the congress "Coltivare la biodiversità. Agricoltura, foreste e territorio: conservare, innovare, pianificare," held in Milan (Italy) June 10-11 2010.

\section{REFERENCES}

AIA. 2010. Milk recording activity. Official Statistics 2009. Accessed Jun. 9, 2010. http://www.aia.it/bollettino/bollettino.htm.

Battaglini, L. M., R. Fortina, S. Tassone, A. Mimosi, and M. Bianchi. 2000. Local breeds conservation and typical products in Piemonte (NW Italy). EFNCP Occasional Publication 23:29-31. European Forum on Nature Conservation and Pastoralism, Argyll, UK.

Battini, M., E. Andreoli, and S. Mattiello. 2010. Il benessere della bovina da latte nei sistemi zootecnici alpini: Confronto tra differenti tipologie di stabulazione e gestione. Quaderno SoZooAlp 6:90-97.

Bielfeldt, J. C., R. Badertscher, K.-H. Tölle, and J. Krieter. 2005. Risk factors influencing lameness and claw disorders in dairy cows. Livest. Prod. Sci. 95:265-271.

Bloom, J. 1983. Traumatic injuries and foot diseases as related to housing systems. Farm animals and welfare. Martinus Nijhoff Publishers, Boston, MA.

Bovolenta, S., D. Pasut, and S. Dovier. 2008. L'allevamento in montagna: Sistemi tradizionali e tendenze attuali. Quaderno SoZooAlp 5:22-29.

Corazzin, M., S. Dovier, E. Bianco, and S. Bovolenta. 2009. Survey on welfare of dairy cow in tie-stalls in mountain area. Ital. J. Anim. Sci. 8(Suppl. 2):610-612.

Corazzin, M., E. Piasentier, S. Dovier, and S. Bovolenta. 2010. Effect of summer grazing on welfare of dairy cows reared in mountain tie-stall barns. Ital. J. Anim. Sci. 9(e59):304-312.

Danuser, J., and G. Regula. 2001. Evaluation der Ökomassnahmen und Tierhaltungsprogramme: Bereich artgerechte Tierhaltung. Vierter Zwischenbericht, Bundesamt für Veterinärwesen, Bern, Switzerland.

EFSA. 2009a. Opinion of the Scientific Panel on Animal Health and Welfare on a request from European Commission on welfare of dairy cows. EFSA J. 1143:1-38.

EFSA. 2009b. Opinion of the Scientific Panel on Animal Health and Welfare on a request from the Commission on the risk assessment of the impact of housing, nutrition and feeding, management and genetic selection on leg and locomotion problems in dairy cows. EFSA J. 1142:1-57.

Fisher, M. V., and A. J. F. Webster. 2009. Breeding and selection goals and animal welfare. Proc. N.Z. Soc. Anim. Prod. 69:135-139.

Hansen, L. B. 2000. Consequences of selection for milk yield from a geneticist's viewpoint. J. Dairy Sci. 83:1145-1150.

Leach, K. A., S. Dippel, J. Huber, S. March, C. Winckler, and H. R. Whay. 2009a. Assessing lameness in cows kept in tie-stalls. J. Dairy Sci. 92:1567-1574.

Leach, K. A., C. Winckler, and H. R. Whay. 2009b. Lameness in dairy and beef cattle and veal calves. Pages 35-41 in Welfare Quality Reports: Assessment of Animal Welfare Measures for Dairy Cattle, Beef Bulls and Veal Calves. Vol 11. B. Forkman and L. Keeling, ed. Cardiff University, Cardiff, UK.

Loberg, J., E. Telezhenko, C. Bergsten, and L. Lidfors. 2004. Behaviour and claw health in tied dairy cows with varying access to exercise in an outdoor paddock. Appl. Anim. Behav. Sci. 89:1-16. 
Lucchesi, V., and S. Mattiello. 2008. Indagine sul benessere dei bovini di razza "Pezzata Rossa d'Oropa" nel Biellese. Quaderno SoZooAlp 5:143-153.

Mattiello, S. 2008. Punti critici e approccio alla valutazione del benessere nei sistemi zootecnici alpini. Quaderno SoZooAlp 5:3042.

Mattiello, S., D. Arduino, M. V. Tosi, and C. Carenzi. 2005. Survey on housing, management and welfare of dairy cattle in tie-stalls in western Italian Alps. Acta Agric. Scand. A 55:31-39.

Mattiello, S., C. Klotz, D. Baroli, M. Minero, V. Ferrante, and E. Canali. 2009. Welfare problems in alpine dairy cattle farms in Alto Adige (Eastern Italian Alps). Ital. J. Anim. Sci. 8(Suppl. 2):628-630.

Mueller-Graf, C., D. Candiani, S. Barbieri, O. Ribò, A. Afonso, E. Aiassa, P. Have, S. Correia, F. De Massis, T. Grudnik, and J. Serratosa. 2008. Risk assessment in animal welfare-EFSA approach. Alternatives to Animal Testing and Experimentation 14(Special issue):789-794.

Welfare Quality ${ }^{\circledR}$. 2009. Welfare Quality ${ }^{\circledR}$ Assessment Protocol for Cattle. Welfare Quality ${ }^{\circledR}$ Consortium, Lelystad, the Netherlands.
Rauw, W. M., E. Kanis, E. N. Noordhuizen-Stassen, and F. J. Grommers. 1998. Undesirable side effects of selection for high production efficiency in farm animals: A review. Livest. Prod. Sci. 56:15-33.

Sandøe, P., B. L. Nielsen, L. G. Christensen, and P. Sørensen. 1999 Staying good while playing God-The ethics of breeding farm animals. Anim. Welf. 8:313-328.

Shanks, R. D., A. E. Freeman, P. J. Berger, and D. H. Kelley. 1978. Effect of selection for milk production on reproductive and general health of the dairy cow. J. Dairy Sci. 61:1765-1772.

Valde, J. P., D. W. Hird, M. C. Thurmond, and O. Osteras. 1997. Comparison of ketosis, clinical mastitis, somatic cell count, and reproductive performance between free stall and tie stall barns in Norwegian dairy herds with automatic feeding. Acta Vet. Scand. 38:181-192.

Zurbrigg, K., D. Kelton, N. Anderson, and S. Millman. 2005. Tie-stall design and its relationship to lameness, injury, and cleanliness on 317 Ontario dairy farms. J. Dairy Sci. 88:3201-3210. 